\title{
RETRACTED ARTICLE: A Novel Eye-Shaped Monopole Antenna for Dual Band and Wideband Communication Applications
}

\author{
Hiwa Taha Sediq ${ }^{1}$ D $\cdot$ Bahman Mohammadi $^{2}$
}

Accepted: 11 November 2020 / Published online: 17 January 2021

(c) Springer Science+Business Media, LLC, part of Springer Nature 2021

The Editor-in-chief has retracted this article because it contains material that substantially overlaps with another article [1].

All authors agree to this retraction. The online version of this article contains the full text of the retracted article as Supplementary Information.

Supplementary Information The online version contains supplementary material available at https://doi. org/10.1007/s11277-020-07973-0.

\section{References}

1. Sediq, H. T., Nourinia, J., Ghobadi, C., \& Mohammadi, B. (2020). A Novel Eye-shaped Monopole Antenna for Wideband and 5G Applications. IETE Journal of Research, 19, 1-1. https://doi. org/10.1080/03772063.2020.1859959.

Publisher's Note Springer Nature remains neutral with regard to jurisdictional claims in published maps and institutional affiliations.

Hiwa Taha Sediq

hiwa_eece@yahoo.com

1 Department of Information Technology, Erbil Polytechnic University, Erbil, Iraq

2 Department of Electrical Engineering, Urmia University, Urmia, Iran 